\title{
COMPARISON BETWEEN MAXILLARY SINUS LIFTING IN COMBINATION WITH IMPLANT PLACEMENT WITH VERSUS WITHOUT BONE GRAFTS (CLINICAL AND RADIOGRAPHIC STUDY)
}

\author{
Omar N. El-Prince* and Hala R. Ragab ${ }^{* *}$
}

\begin{abstract}
Introduction: Placement of implants in the posterior maxillary region is usually complicated by maxillary sinuses pneumatization, post-extraction bone resorption, and unfavorable quality of alveolar bone. Hence, the height of the residual bone is reduced which makes placing the standard implant difficult. Maxillary sinus lifting is one possible solution.
\end{abstract}

Objective: The aim of this study was to evaluate the clinical and radiographical maxillary sinus lifting technique without graft material versus sinus lifting technique with graft material.

Materials and Methods: this study was made as a clinical randomized controlled trial, the study sample included 14 patients. The sample was selected to match the inclusion and exclusion criteria. The selected patients were divided into two equal groups, both groups had gone through lifting of maxillary sinus simultaneously with implant placement, group1: maxillary sinus lifting was made for seven patients in combination with implant placement without bone graft. In group2: maxillary sinus lifting was made for seven patients in combination with implant placement with bone graft (Osteon ${ }^{\mathrm{TM}}$ II bone graft material). Clinical and radiographic evaluation was done through 6 months post-operatively.

Results: Regarding postoperative clinical evaluation, group 1 had mild pain and edema postoperatively than that of group 2 . The postoperative radiographical evaluation bone was evidenced and recorded around all implants at six months postoperatively in both groups, however, no statistical significant difference was recorded between both groups in the amount of bone density formed after 6 months postoperatively.

Conclusion: Similar results can be reached with or without the use of bone graft materials in the sinus lifting procedure with implant placement.

* Lecturer of Oral and Maxillofacial Surgery, Faculty of Dentistry, MUST University, Egypt.

**Assistant Professor of Oral and Maxillofacial Surgery, Faculty of Dentistry, Alexandria University, Egypt. 


\section{INTRODUCTION}

Missing teeth replacement has become one of the most crucial needs for patients who aspire to restore esthetics and function in the dental clinics. Different modalities of treatment are available for such procedure, for instance, removable partial denture, fixed partial denture or dental implant. Each treatment modality is a possible option and it has its own advantages and disadvantages ${ }^{(1)}$.

Implant treatment is an excellent option for replacing missing teeth. Brånemark et al. in $1974^{(2)}$ was the first to introduce the term of osseointegration which describes the bone to implant contact. Albrektsson et al. in $2003^{(3)}$ described the same term of osseointegration but at the light microscope level which is "direct contact between living bone and implant". Thanks to the augmentation procedure, Contraindications for implants are being reduced substantially. Nowadays, insufficient quantity of the alveolar bone is not an absolute contraindication for implant placement ${ }^{(4)}$.

Placement of implants in the posterior maxillary region is usually complicated by maxillary sinuses pneumatization, post-extraction bone resorption, and unfavorable quality of alveolar bone. Hence, the height of remaining residual bone is reduced which makes placing the standard implant difficult ${ }^{(5)}$. Maxillary sinus lifting is one possible solution ${ }^{(6)}$.

Maxillary sinus lifting and augmentation with autologous bone graft was first introduced by Boyne in $1980^{\text {(7). }}$. Modification and improvement of this technique has been done by Tatum in $1986^{(8)}$ who introduced the lateral approach by fenestrating the bony buccal wall of maxillary sinus and then lifting the Schneiderian membrane. Wood and More in $1994{ }^{(9)}$ modified this technique by grafting the maxillary sinus with intra-orally harvested autogenous bone to facilitate implant placement in the maxillary edentulous jaw.
Grafting material should be bioactive and biocompatible. It should maintain mechanical stability and volume during the initial healing and then subsequently resorbs completely, being replaced by newly formed bone ${ }^{(10)}$. Bone substitutes should act via three different mechanisms: osteoinduction, osteoconduction and osteogenesis ${ }^{(11)}$.

For over than 30 years, different clinical and experimental researches have been done based on the opinion of necessity of the maxillary sinus grafting and great industrial investments have been undertaken to develop products for augmentation of the sub-antral area. Eventually, the idea of a graft-less maxillary sinus augmentation has been evolved ${ }^{(12)}$.

Boyne (1993) ${ }^{(13)}$ presented experimental results from a primate study in 1993 in which implants were placed without grafts to protrude $5 \mathrm{~mm}$ into the sinus floor and experienced bone formation.

The aim of the current study was to make a comparison between the maxillary sinus lifting techniques in combination with implant placement with and without graft material.

\section{MATERIALS AND METHODS}

This study was carried out as a randomized controlled clinical trial. In this study 14 patients requiring dental implants rehabilitation in the posterior region of maxilla, where the alveolar ridge was resorbed substantially and elevation of maxillary sinus floor was indicated; all patients were selected from the Outpatient Clinic of Oral and Maxillofacial Surgery Department, Faculty of Dentistry, Alexandria University.

The inclusion criteria in this study was as following: Patients had unilateral or bilateral free end saddle ( premolar-molar region ) in the maxillary posterior region, sub-antral bone was below $7 \mathrm{~mm}$, Patients' ages range were from 30 to 60 years old, all patients had an acceptable inter-arch space for the potential prosthesis, and adequate oral hygiene. 
The exclusion criteria was: patients who had sinus pathologies or chronic sinusitis, heavy smokers and/or alcoholism patients, patients with parafunctional habits, patients who had any systemic disease directly affecting upon surgical procedure and /or bone healing, patients on medications that may affect the surgical procedure and patients with psychiatric disorders.

Random allocation of the selected patients was carried out in two equal groups: Group 1: which included 7 patients, where maxillary sinus lifting was performed simultaneously with implant placement ( Dentium Co., Ltd. Seoul, Korea ) without adding bone grafts and Group 2: which included 7 patients, where maxillary sinus lifting was performed simultaneously with implant placement with adding bone grafts (Osteon ${ }^{\mathrm{TM}} \mathrm{II}-0.25 \mathrm{cc}$ ) (Table 1).

\section{Pre-surgical phase}

All patients were evaluated by proper case history, clinical examination, radiographic examination via Cone beam computed tomography CBCT (J. Morita, at $8 \mathrm{~mA}, 90 \mathrm{KV}$, Japan) and OnDemand $3 \mathrm{D}^{\mathrm{TM}}$ software program (OnDemand 3D ${ }^{\mathrm{TM}}$ Goddard Way, Suite 250 Irvine, CA 92618 USA) to decide the indication for maxillary sinus lifting and for assessment of the amount of bone below the maxillary sinus floor. (Figure 1)

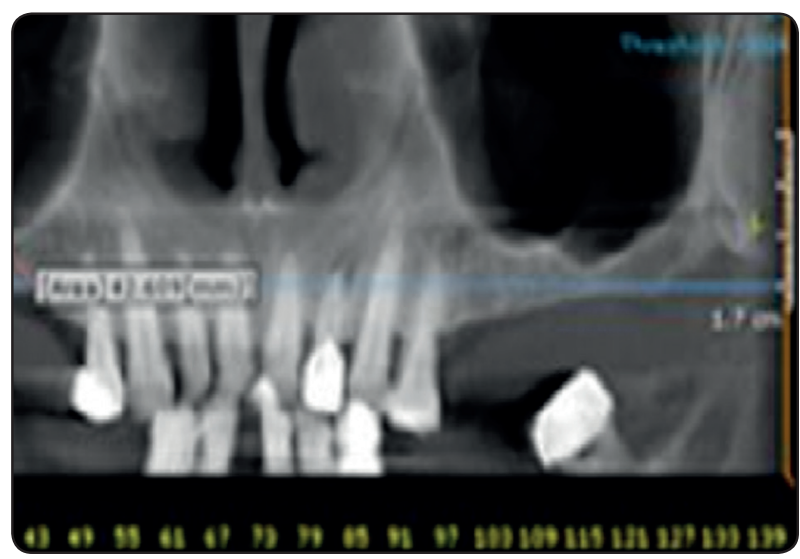

Fig. (1): Radiographic preoperative view for patient indicated for maxillary sinus lift in group 1

TABLE (1): Showing implants number and size regarding each patient.

\begin{tabular}{|c|c|c|c|c|}
\hline \multirow[b]{2}{*}{$\begin{array}{l}\text { Patient } \\
\text { number }\end{array}$} & \multicolumn{2}{|c|}{ Group 1} & \multicolumn{2}{|c|}{ Group 2} \\
\hline & $\begin{array}{c}\text { Number of implants in } \\
\text { one side }\end{array}$ & Implant size & $\begin{array}{l}\text { Number of implants } \\
\text { in one side }\end{array}$ & Implant size \\
\hline 1 & 2 & $\begin{array}{l}3 \times 11 \mathrm{~mm} \\
3.6 \times 12 \mathrm{~mm}\end{array}$ & 1 & $4 \times 12 \mathrm{~mm}$ \\
\hline 2 & 3 & $\begin{array}{c}4 \times 12 \mathrm{~mm} \\
4.5 \times 10 \mathrm{~mm} \\
4.5 \times 10 \mathrm{~mm}\end{array}$ & 3 & $\begin{array}{c}3.6 \mathrm{x} 12 \mathrm{~mm} \\
4 \times 14 \mathrm{~mm} 4.5 \times 14 \mathrm{~mm}\end{array}$ \\
\hline 3 & 1 & $3.6 \times 10 \mathrm{~mm}$ & 2 & $\begin{array}{l}4 \times 10 \mathrm{~mm} \\
5 \times 14 \mathrm{~mm}\end{array}$ \\
\hline 4 & 2 & $\begin{array}{l}3.6 \times 12 \mathrm{~mm} \\
3 \times 11 \mathrm{~mm}\end{array}$ & 2 & $\begin{array}{c}5 \times 12 \mathrm{~mm} \\
4.5 \times 12 \mathrm{~mm}\end{array}$ \\
\hline 5 & 2 & $\begin{array}{c}5 \times 8 \mathrm{~mm} \\
4.5 \times 10 \mathrm{~mm}\end{array}$ & 2 & $\begin{array}{l}3 \times 11 \mathrm{~mm} \\
4 \times 14 \mathrm{~mm}\end{array}$ \\
\hline 6 & 2 & $\begin{array}{l}4 \times 10 \mathrm{~mm} \\
3 \times 13 \mathrm{~mm}\end{array}$ & 2 & $\begin{array}{l}3.6 \times 14 \mathrm{~mm} \\
4.5 \times 12 \mathrm{~mm}\end{array}$ \\
\hline 7 & 1 & $4 \times 10 \mathrm{~mm}$ & 2 & $\begin{array}{l}4 \times 14 \mathrm{~mm} \\
3.6 \mathrm{x} 14 \mathrm{~mm}\end{array}$ \\
\hline
\end{tabular}


Consultation of ENT was made to exclude any pathological or inflammatory disorders related to the maxillary sinus before the surgical procedure.

Full arch Impressions were taken for the maxillary and mandibular arches and then diagnostic wax up was made on the study cast to fabricate a surgical-vacuum-formed stent to locate the implants' osteotomy site during surgery.

\section{Surgical Procedure}

All surgical procedures in both groups were performed using local maxillary nerve block technique anesthesia, with a strict aseptic conditions.

All patients in both groups had their maxillary sinus lifting procedure simultaneously with implant placement through buccal antral approach as following: A mid-crestal or a slightly palatal incision was performed, leaving at least three $\mathrm{mm}$ of attached gingiva on the facial aspect of the incision with anterior and posterior vertical releasing incisions. These vertical incisions should be at least $5 \mathrm{~mm}$ away from the planned implant osteotomy site then a mucoperiosteal full-thickness flap was raised and the lateral aspect of the maxillary sinus was exposed. The buccal window osteotomy was performed at the premolars -molar area (Figure 2). The schniderian membrane was meticulously dissected and lifted using Sinus membrane periosteal elevators (Dentium Advanced Sinus Lift Set). The elevator was glided along the bone in three sides of the window, anterior, inferior and posterior to ensure release of the membrane without tearing from the sharp bony margins. Drilling for placement of implant was done guided by the preformed surgical stent. Implant of suitable size was initially inserted at the apical aspect of the alveolar ridge osteotomy to maintain the Sinus membrane in the desired elevated position around the implant in a tenting fashion.

In group 1: the space created between the implant and the sinus membrane was lifted unfilled without any type of bone augmentations materials (Figure 3). In group 2: the space created between the implant and the sinus membrane was filled with Osteon ${ }^{\mathrm{TM}} \mathrm{II}$ bone graft material (Figure 4). Finally the flap repositioning and closure with sutures were carried out in both groups.

\section{Post-surgical instructions and medications}

All patients were advised to: apply Cold fomentation over the cheek at five minutes interval for one hour on the first day, and to avoid any actions that might create high intranasal pressure or vacuum such as sneezing, nose blowing or any other actions.
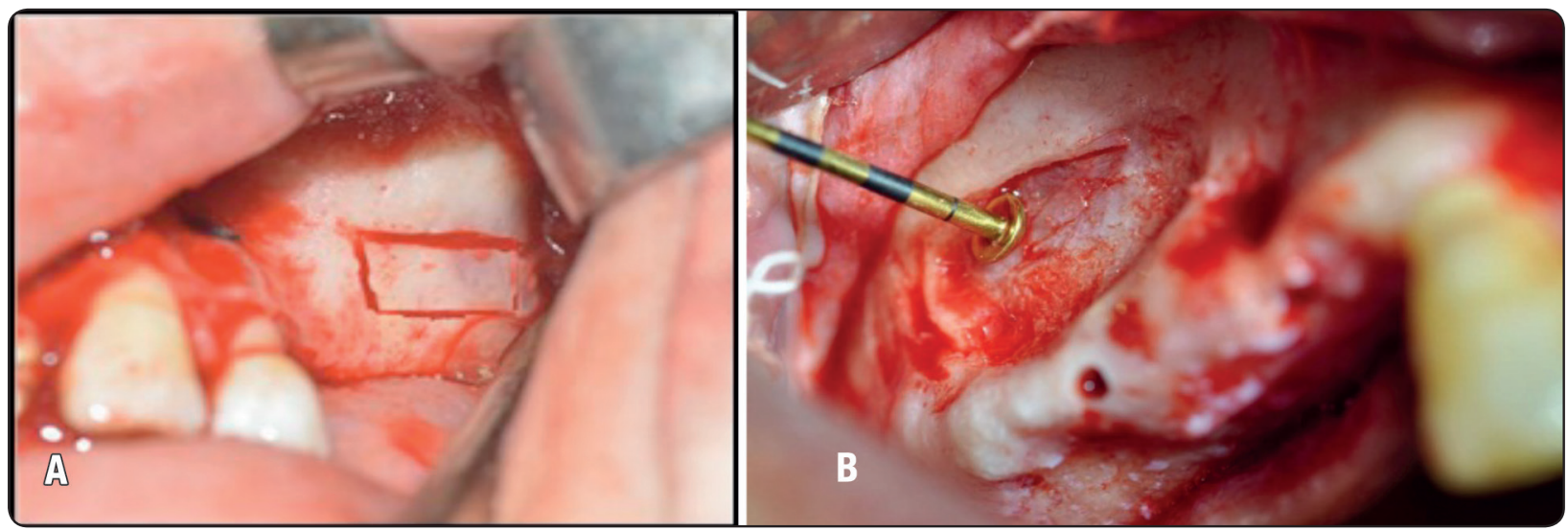

Fig. (2): a-Buccal window osteotomy was performed at the premolars -molar area b- Elevation of the schniderian membrane 
Patients were also instructed to avoid using straws for drinking for a week. Patients were instructed to avoid wearing any prosthesis over the surgical site for at least one week after surgery, and a soft high nutrient diet was recommended.

Postoperative medication included broad spectrum antibiotic Amoxicillin $875 \mathrm{mg}+$ Clavulanic acid $125 \mathrm{mg}$ tablets (Augmentin 1 gram tablet GlaxoSmithKline group. Co. Egypt) every 12 hours for five days to avoid post-operative infection. Non-steroidal anti-inflammatory analgesic (Brufen 600mg tablets Abbott house. Co. Egypt) every 8 hours for three days to avoid the possibility of pain. Nasal Decongestant as Oxymetazoline (Afrin 0.05 nasal drops Schering plough Co. Egypt) every 8 hours for five days.

\section{Postoperative evaluation}

All patients were examined at intervals of 7 days, 1 month, 3moths, and 6 month postoperatively. Pain and discomfort were examined using Visual Analogue Scale (VAS) (19). Edema was evaluated by a visual descriptor analogue scale (20) used to indicate presence/absence of edema and inflammation. Wound healing was evaluated by Early Wound Healing Index (EHI) (21) to provide a more objective assessment of postoperative wound healing quality.

Immediate Postoperative and 6 month postoperative CBCT scan were conducted with the same settings and apparatus as the preoperative scans to evaluate the amount of vertical bone height gained, amount of bone density, and amount of marginal bone loss postoperatively.

For evaluating of the amount of bone density, the data from CBCT was recorded in Hounsfield unit (HU) and comparison was made between preoperative (base line), immediate postoperative and 6 month postoperative. (Figure 5)

The data from CBCT also was recorded in millimeter $(\mathrm{mm})$ and comparison was made between preoperative, immediate postoperative and 6 month

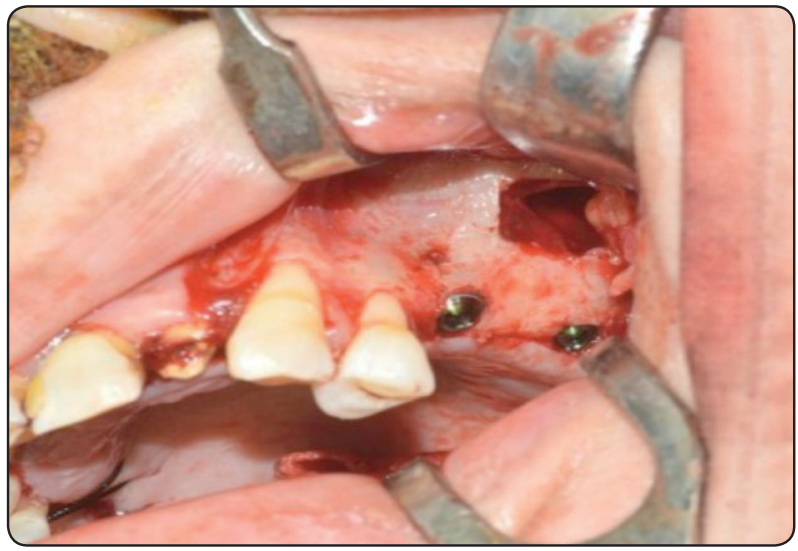

Fig. (3): Space created between the implant and the schniderian membrane was lifted unfilled without any type of bone augmentations materials in group 1 .

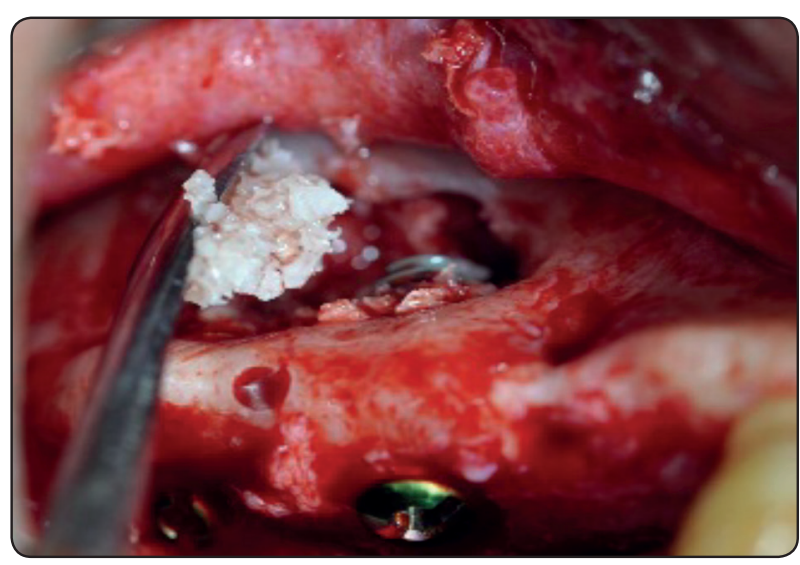

Fig. (4):The space created between the implant and the schniderian membrane was filled with Osteon TM II bone graft material in group 2 .

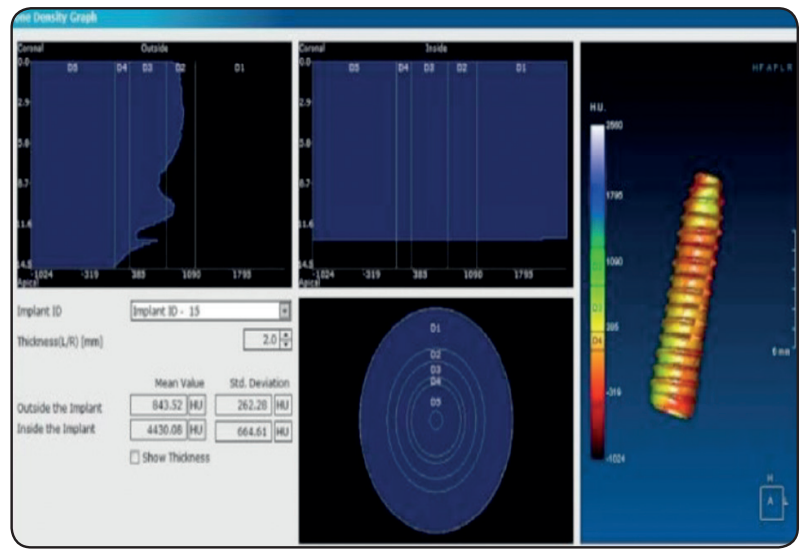

Fig. (5): Bone density determination using OnDemand $3 \mathrm{D}^{\mathrm{TM}}$ software showing mean bone density around implant. 
postoperative for evaluation of vertical bone height gained.

To assess the amount of marginal bone loss postoperatively, data from CBCT also was recorded in millimeter $(\mathrm{mm})$ and comparison was made between immediate postoperative and 6 month postoperatively.

\section{Prosthetic phase}

All implants stability were checked after 6 months postoperatively using Osstell (Osstell Co. Sweden) implant stability meter before prosthetic loading. Reopening of the implant side was performed by punch technique in both groups. Gingival formers was inserted for 1-2 weeks to provide appropriate gingival contour at implants' collar area. Impression was taken using implant analogues. Definitive porcelain fused to metal crowns was delivered to all patients after 6 months for both groups.

\section{RESULTS}

In this study, in group 1: seven patients had maxillary sinus lifting simultaneously with implant placement without adding bone grafts and in group 2 seven patients had maxillary sinus lifting simultaneously with implant placement and bone graft. The selected patients were six males (43\% of patients) and eight females (57\% of patients), and their age ranged from 33-59 years with a mean age of 44.5 years.

In group 1 the mean height of the alveolar ridge from the marginal crest to floor of the maxillary sinus was $4.37 \pm 1.19 \mathrm{~mm}$ (Range: $3.1-7.0 \mathrm{~mm}$ ), while in group 2 mean height of the alveolar ridge from the marginal crest to floor of the maxillary sinus was $4.44 \pm 1.17 \mathrm{~mm}$ (Range: $2.92-7.0 \mathrm{~mm}$ ).

Regarding the number of implants placed, thirteen implants were placed in group 1 patients and fourteen implants were placed in group 2 patients.

\section{Post-operative evaluation}

\section{Clinical evaluation}

Regarding postoperative pain evaluation: in group 1, five patients experienced mild pain $(\mathrm{VAS}=1)$ and two patients experienced moderate pain (VAS=2) at surgical site for 1-5 days duration. In group 2, two patients experienced mild pain (VAS=1), four patients experienced moderate pain $(\mathrm{VAS}=2)$ and one patient experienced moderate to severe pain $(\mathrm{VAS}=5)$ at surgical site for 1-5 days duration (Table 2).

TABLE (2): Post-operative pain (VAS) .

\begin{tabular}{|c|c|c|}
\hline \multirow{2}{*}{ Patient's number } & \multicolumn{2}{|c|}{ Post- operative edema } \\
\cline { 2 - 3 } & Group 1 & Group 2 \\
\hline 1 & Grade 1 & Grade 2 \\
\hline 2 & Grade 2 & Grade 1 \\
\hline 3 & Grade 1 & Grade 3 \\
\hline 4 & Grade 1 & Grade 1 \\
\hline 5 & Grade 2 & Grade 3 \\
\hline 6 & Grade 1 & Grade 3 \\
\hline 7 & Grade 1 & Grade 2 \\
\hline
\end{tabular}

TABLE (3): Post-operative edema.

\begin{tabular}{|c|c|c|}
\hline \multirow{2}{*}{ Patient's number } & \multicolumn{2}{|c|}{ Post- operative pain (VAS) } \\
\cline { 2 - 3 } & Group 1 & Group 2 \\
\hline 1 & 1 & 2 \\
\hline 2 & 2 & 1 \\
\hline 3 & 1 & 5 \\
\hline 4 & 1 & 1 \\
\hline 5 & 2 & 2 \\
\hline 6 & 1 & 2 \\
\hline 7 & 1 & 2 \\
\hline
\end{tabular}


Regarding post-operative edema in group 1 five patients experienced a slight swelling grade 1 edema,twopatientsexperiencedmildswelling grade 2 edema that lasted for five days and then the edema subsided gradually. However in group 2 two patients had experienced a slight swelling grade 1 edema, two patients had experienced a mild swelling grade 2 edema, and three patients had experienced a severe swelling grade 3 edema, that lasted for five days and then the edema subsided gradually (Table 3).

For evaluation of postoperative surgical wound healing in group 1 five patients had experienced grade 2 Early Wound Healing Index (EHI) and two patients had experienced grade 3 Early Wound Healing Index (EHI). However in group 2 three patients had experienced grade 2 Early Wound Healing Index (EHI) and two patients had experienced grade 1 Early Wound Healing Index (EHI) and two patients had experienced grade 3 Early Wound Healing Index (EHI)( Table 4 ).

TABLE (4): Post-operative Early Wound Healing Index (EHI).

\begin{tabular}{|c|c|c|}
\hline \multirow{2}{*}{ Patient's number } & \multicolumn{2}{|c|}{ Wound Healing Index (EHI) } \\
\cline { 2 - 3 } & Group 1 & Group 2 \\
\hline 1 & Grade 2 & Grade 2 \\
\hline 2 & Grade 3 & Grade 1 \\
\hline 3 & Grade 2 & Grade 3 \\
\hline 4 & Grade 2 & Grade 1 \\
\hline 5 & Grade 3 & Grade 3 \\
\hline 6 & Grade 2 & Grade 2 \\
\hline 7 & Grade 2 & \\
\hline
\end{tabular}

Implant stability was checked for all implants using osstell (Osstell Co. Sweden) 6 months postoperatively. In group 1 the minimum ISQ number recorded was 61 and the maximum was 79. However in group 2 the minimum ISQ number recorded was 64 and the maximum was 77.

\section{Radiographic evaluation}

The amount of bone density was evaluated by comparing the preoperative, the immediate postoperative and 6 months postoperative CBCT images for all twenty seven implants in both groups. The amount of bone density of newly formed bone in group 2 was not significantly higher than that of group 1 after six months postoperatively (Table 5).

TABLE (5): Comparison between the two groups according to bone density of the newly formed bone after 6 months.

\begin{tabular}{|c|c|c|c|c|}
\hline Bone density & $\begin{array}{c}\text { Group 1 } \\
(\mathbf{n = 1 3})\end{array}$ & $\begin{array}{c}\text { Group 2 } \\
(\mathbf{n = 1 4})\end{array}$ & $\mathbf{t}$ & $\mathbf{p}$ \\
\hline \multicolumn{5}{|c|}{ 6 months post-operative } \\
\hline Min. - Max. & $\begin{array}{c}855.05 \\
-1413.72\end{array}$ & $\begin{array}{c}843.68 \\
-1243.91\end{array}$ & & \\
\hline Mean \pm SD. & $\begin{array}{c}1128.10 \\
\pm 186.98\end{array}$ & $\begin{array}{c}1119.74 \\
\pm 213.12\end{array}$ & 2.074 & 0.57 \\
\hline Median & 1152.33 & 1134.87 & & \\
\hline
\end{tabular}

$t, p: t$ and $p$ values for Student t-test for comparing between the two groups Statistically significant at $p \leq 0.05$

The amount of vertical bone height gained was evaluated by subtracting the difference between immediate postoperative bone height gained and six months postoperatively. There were no statistically significant differences between both groups in the amount of vertical bone height gained after 6 months postoperatively (Table 6). 
TABLE (6): Comparison between the two groups according to vertical bone height gained after 6 months.

\begin{tabular}{|c|c|c|c|c|}
\hline $\begin{array}{c}\text { Amount } \\
\text { of vertical } \\
\text { height }\end{array}$ & $\begin{array}{c}\text { Group 1 } \\
(\mathbf{n = 1 3})\end{array}$ & $\begin{array}{c}\text { Group 2 } \\
(\mathbf{n}=\mathbf{1 4})\end{array}$ & $\mathbf{T}$ & $\mathbf{p}$ \\
\hline \multicolumn{5}{|c|}{ 6 months post-operative } \\
\hline Min.- Max. & $7.43-12.44$ & $7.52-12.35$ & & \\
\hline Mean \pm SD. & $10.0 \pm 1.80$ & $10.0 \pm 2.01$ & 1.963 & 0.6 \\
\hline Median & 9.60 & 9.69 & & \\
\hline
\end{tabular}

$t, p: t$ and $p$ values for Student t-test for comparing between the two groups

\section{Statistically significant at $p \leq 0.05$}

Data were also collected for each implant regarding the amount of marginal bone loss by subtracting the difference between the marginal bone level in the immediate postoperative phase and six months later. There were no statistically significant differences between both groups in the amount of marginal bone loss after 6 months (Table 3).

TABLE (3): Comparison between the two groups according to marginal bone loss after 6 months.

\begin{tabular}{|c|c|c|c|c|}
\hline $\begin{array}{c}\text { Marginal bone } \\
\text { loss after 6 } \\
\text { month }\end{array}$ & $\begin{array}{c}\text { Group 1 } \\
(\mathbf{n = 1 3})\end{array}$ & $\begin{array}{c}\text { Group 2 } \\
(\mathbf{n = 1 4})\end{array}$ & $\mathbf{T}$ & $\mathbf{p}$ \\
\hline Min. - Max. & $0.40-1.62$ & $0.47-1.53$ & & \\
\hline Mean + SD. & $1.12 \pm 0.26$ & $1.52 \pm 0.32$ & 2.806 & 0.1 \\
\hline Median & 1.20 & 1.23 & & \\
\hline
\end{tabular}

$t, p$ : $t$ and $p$ values for Student t-test for comparing between the two groups

Statistically significant at $p \leq 0.05$

\section{DISCUSSION}

Placement of implants in the posterior maxillary region is usually complicated by maxillary sinuses pneumatization, post-extraction bone resorption, and unfavorable quality of alveolar bone. Hence, the vertical height of the residual bone reduced which makes placing the standard implant difficult ${ }^{(5)}$. Maxillary sinus lifting is one possible solution ${ }^{(6)}$.

In this study, evaluation of the maxillary sinus lifting technique without adding bone graft versus with adding bone graft has been accomplished by selecting 14 patients, with edentulous area at the premolar-molar region and indicated for implant placement. The patients were divided into two equal groups for comparison between the two techniques clinically and radiographically.

In this study the minimum alveolar ridge height below the maxillary sinus floor before surgery was 2.9 $\mathrm{mm}$. the average of bone height in group 1 was 4.37 $\pm 1.19 \mathrm{~mm}$ and in group 2 was $4.44 \pm 1.17 \mathrm{~mm}$ that achieved a satisfied primary stability to the inserted implant. This was in agreement with Nedir et al (22) in 2006 who confirmed that the minimal requirement for achieving primary stability is the presence of a cortical bone layer. This was also in accordance with He et al ${ }^{(23)}$ in 2011 who showed that it was possible to achieve implant stability even when the available bone height was limited down to 4-5 $\mathrm{mm}$.

Despite the fact that all implants in group 1 were placed in tandem with maxillary sinus membrane lifting without adding any grafted material, bone formation was evidenced and recorded around all implants at six months postoperatively in both groups. This result emphasized the fact that the Schneiderian membrane itself has an osteogenic effect and came in accordance with the same result stated by Ellegaard et al in (1997) ${ }^{(14)}$, Lundgren et al (2004) ${ }^{(15)}$, Hatano et al (2007) ${ }^{(16)}$, Borges et al (2011) $^{(17)}$, He et al (2013) ${ }^{(18)}$, Sani et al (2008) ${ }^{(24)}$, and Balleri et al (2012) ${ }^{(25)}$. These results may be explained by the maintenance of the space between 
the apex of the implant and the sinus membrane with blood, assisting in bone formation in this region.

The present study found weak negative correlation insignificant statistically difference between group 1 and group 2 in the amount of bone density formed after 6 months postoperatively. This result was in agreement with the study that has been done by Altintas et al. (2013) ${ }^{(26)}$ who found that there was no statistically significant difference in the amount of newly formed bone after 6 months postoperatively in a group which no graft has been used versus a group with bone graft in the sinus lifting procedure.

\section{CONCLUSIONS}

Although the successful use of graft materials in maxillary sinus lifting is reported in literature, this procedure is feasible without graft material and very similar results can be seen with and without the use of graft material. Furthermore, maxillary sinus lift surgery without the use of graft material result in a reduced surgical time and lower total cost compared to surgery with the use of grafts.

\section{CONFLICT OF INTEREST}

The authors declare that they have no conflicts of interest.

\section{REFERENCES}

1. Christensen GJ. Elective vs. mandatory dentistry. J Am Dent Assoc. 2000;131:1496-8.

2. Branemark AI, Hansson BO, Adell R, Breine U, Lindstrom $\mathrm{J}$, Hallen $\mathrm{O}$, et al. Osseointegrated implants in the treatment of the orthognathic treated jaw. Experience from a 10-year period. Scand J Plast Reconstr Surg Suppl. 1974;16:3-24.

3. Albrektsson T, Johansson C. Osteoinduction, osteoconduction and osseointegration. Eur Spine J. 2003; 2:12-22.

4. Jensen OT. The sinus bone graft. Chicago, London: Quintessence Publ.; 1999. p. 52.

5. Misch CE, Steignga J, Barboza E, Misch-Dietsh F, Cianciola LJ, Kazor C. Short dental implants in posterior partial edentulism: A multicenter retrospective 6-year case series study. J Periodontal. 2006;77:1340-7.
6. Del Fabbro M, Rosano G, Taschieri S. Implant survival rates after maxillary sinus augmentation. Eur J Oral Sci. 2008;116:497-506.

7. Boyne PJ. Grafting of maxillary sinus floor with autogenous marrow and bone. J Oral Surg. 1980;38:613-6.

8. Tatum H Jr. Maxillary and sinus implant reconstructions. Dent Clin North Am. 1986;30:207-29.

9. Wood RM, Moore DL. Grafting of the maxillary sinus with intraorally harvested autogenous bone in order to place implant in the edentolous jaw. Int J Oral Maxillofac Implants. 1994;3:201-12.

10. Isaksson S. Aspects of bone healing and bone substitute incorporation. An experimental study in rabbit skull bone defects. Swed Dent J Suppl. 1992;84:1-46.

11. Pjetursson BE, Tan WC, Zwahlen M, Lang NP. A systematic review of the success of sinus floor elevation and survival of implants inserted in combination with sinus floor elevation. J Clin Periodontol. 2008;35:216-40.

12. Marx RE, Carlson ER, Eichstaedt RM, Schimmele SR, Strauss JE, Georgeff KR. Platelet-rich plasma: Growth factor enhancement for bone grafts. Oral Surg Oral Med Oral Pathol Oral Radiol Endod. 1998;85:638-46.

13. Boyne PJ. Analysis of performance of root-form endosseous implants placed in the maxillary sinus. J Long Term Eff Med Implants. 1993;3:143-59.

14. Ellegaard B, Kolsen-Petersen J, Baelum V. Implant therapy involving maxillary sinus lift in periodontally compromised patients. Clin Oral Implants Res. 1997;8:305-15.

15. Lundgren S, Andersson S, Gualini F, Sennerby L. Bone reformation with sinus membrane elevation: a new surgical technique for maxillary sinus floor augmentation. Clin Implant Dent Relat Res. 2004;6:165-73.

16. Hatano N, Sennerby L, Lundgren S. Maxillary sinus augmentation using sinus membrane elevation and peripheral venous blood for implant-supported rehabilitation of the atrophic posterior maxilla: case series. Clin Implant Dent Relat Res. 2007;9:150-5.

17. Borges FL, Dias RO, Piattelli A, Onuma T, Gouveia Cardoso LA, Salomao M, et al. Simultaneous sinus membrane elevation and dental implant placement without bone graft: a 6-month follow-up study. J Periodontol. 2011; 82:403-12.

18. He L, Chang X, Liu Y. Sinus floor elevation using osteotome technique without grafting materials: a 2-year retrospective study. Clin Oral Implants Res. 2013;24:63-7. 
19. Chang DJ, Bird SR, Bohidar NR, King T. Analgesic efficacy of rofecoxib compared with codeine/acetaminophen using a model of acute dental pain. Oral Surg Oral Med Oral Pathol Oral Radiol Endod. 2005;100:e74-80.

20. Henrikson PA, Thilander H, Wåhlander LA. Voltaren as an analgesic after surgical removal of a lower wisdom tooth. Int J Oral Maxillofac Surg.1985;14:333-8.

21. Wachtel H, Schenk G, Bohm S. Weng D, Zuhr O, Hurzeler M. Micro-surgical access flap and enamel matrix derivative for the treatmentof periodontal intrabony defects: A controlled clinical study. J Clin Periodontal. 2003; 30:496-504.

22. Nedir R, Bischof M, VazquezL, Szmukler-Moncler S, Bernard JP. Osteotome sinus floor elevation without grafting material: a 1year prospective pilot study with ITI implants. Clin Oral Implants Res. 2006;17:679-86.
23. He L, Chang X, Liu Y. Sinus floor elevation using osteotome technique without grafting materials: a 2-year retrospective study. Clin Oral Implants Res. 2011;8:1-5.

24. Sani E, Veltri M, Cagidiaco MC, Balleri P, Ferrari M. Sinus membrane elevation in combination with placement of blasted implants: a 3-year case report of sinus augmentation without grafting material. Int J Oral MaxillofacSurg. 2008;37:966-9.

25. Balleri P, Veltri M, Nuti N, Ferrari M. Implant placement in combination with sinus membrane elevation without Biomaterials: a 1-year study on 15patients. Clin Implant Dent Relat Res. 2012;14:682-9.

26. Altintas NY, Senel FC, Kayımaz S, Taskesen F, Pampu AA. Comparative radiologic analyses of newly formed bone after maxillary sinus augmentation with and without bone grafting. J Oral Maxillofac Surg. 2013;71:1520-30. 